\title{
5,7,12,14-Tetraphenyl-Substituted 6,13-Diazapentacenes as Versatile Organic Semiconductors: Characterization in Field Effect Transistors
}

\author{
Miriam Hauschild ${ }^{\mathrm{a}, \mathrm{b}}$ \\ Michal Borkowski ${ }^{c}$ \\ Pavlo O. Drald (i) \\ Tomasz Marszalek ${ }^{\text {, e }}$ (i) \\ Frank Hampel ${ }^{f}($ i) \\ Gaozhan Xie ${ }^{\mathrm{a}}$ \\ Jan Freudenberg ${ }^{a}$ \\ Uwe H. F. Bunz ${ }^{* a}$ \\ Milan Kivala*a,b (i)
}

${ }^{a}$ Organisch-Chemisches Institut, Ruprecht-Karls-Universität Heidelberg, Im

Neuenheimer Feld 270, 69120 Heidelberg, Germany

${ }^{\mathrm{b}}$ Centre for Advanced Materials, Im Neuenheimer Feld 225, 69120 Heidelberg,

Germany

Department of Molecular Physics, Lodz University of Technology, Zeromskiego 116, 90-924 Lodz, Poland

${ }^{\mathrm{d}}$ State Key Laboratory of Physical Chemistry of Solid Surfaces, Fujian Provincial Key Laboratory of Theoretical and Computational Chemistry, Department of Chemistry, College of Chemistry and Chemical Engineering, Xiamen University, Xiamen 361005, China

e Max Planck Institute for Polymer Research, Ackermannweg 10, 55128 Mainz, Germany

${ }^{f}$ Department of Chemistry and Pharmacy, Friedrich-Alexander-University Erlangen-

Nürnberg, Nikolaus-Fiebiger-Str. 10, 91058 Erlangen, Germany

milan.kivala@oci.uni-heidelberg.de, uwe.bunz@oci.uni-heidelberg.de

Received: 22.04.2020

Accepted after revision: 16.05 .2020

DOI: 10.1055/s-0040-1713856; Art ID: om-20-0010oa

License terms: $(9)(1) \ominus$

(c) 2020. The Author(s). This is an open access article published by Thieme under the terms of the Creative Commons Attribution-NonDerivative-NonCommercial-License, permitting copying and reproduction so long as the original work is given appropriate credit. Contents may not be used for commercial purposes, or adapted, remixed, transformed or built upon. (https://creativecommons.org/licenses/by-nc-nd/4.0/).

Abstract We report the synthesis of 5,7,12,14-tetraphenyl-substituted 6,13-dihydro-6,13-diazapentacene and its fully aromatic 6,13diazapentacene congener. Both arylated diazapentacenes were characterized by $\mathrm{X}$-ray crystallography to investigate their solid-state structures and by UV-vis spectroscopy and cyclic voltammetry to unveil their electronic properties. The experimental results are complemented with theoretical investigations. The semiconductor properties of both diazapentacene derivatives were assessed in organic field-effect transistors, whereby the fully aromatized compound showed comparably less abundant n-type behavior.

Key words diazapentacenes, polycyclic aromatic hydrocarbons, tetrasubstitution, organic semiconductors, organic field-effect transistors

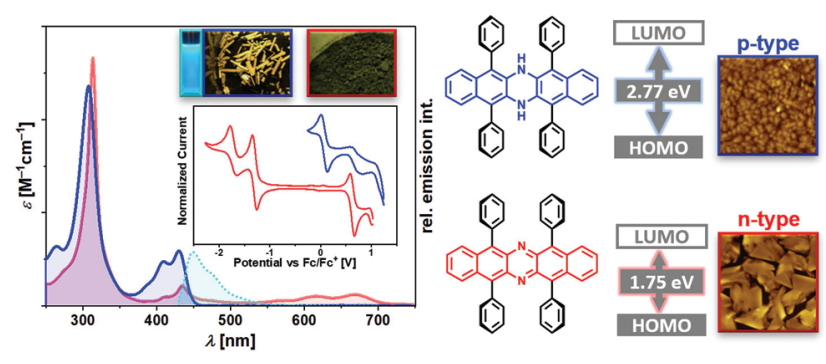

\section{Introduction}

Pentacene is widely studied as a p-type semiconductor in organic electronic applications. With a hole mobility of up to $5 \mathrm{~cm}^{2} \mathrm{~V}^{-1} \mathrm{~s}^{-1}$ it is a leading organic semiconductor for organic field-effect transistors (OFETs). ${ }^{1}$ However, pentacene has major disadvantages, such as low chemical stability and low solubility. ${ }^{2}$ The incorporation of heteroatoms into the carbonaceous scaffold changes the molecular properties in an advantageous fashion. ${ }^{3,4}$ The introduction of nitrogen atoms into the pentacene scaffold results in the so-called $\mathrm{N}$ heteropentacenes, belonging to the family of $\mathrm{N}$-heteroacenes or azaacenes. In this context, the number, position, and valency of the incorporated nitrogen atoms influence the stability, solubility, solid-state properties, and electronic structure of the $N$-heteropentacene. ${ }^{4-8}$

Formally replacing the two middle-ring $\mathrm{sp}^{2}$-carbon atoms of pentacene with nitrogen atoms affords 6,13dihydro-6,13-diazapentacene (DHDAP), which was synthesized first by Hinsberg in $1901 .^{9}$ DHDAP shows enhanced stability and solubility compared to pentacene. ${ }^{6}$ However, besides the syntheses of the fully aromatic 6,13-diazapentacene (DAP) in $1962,{ }^{10}$ as well as 6,13-diazapentacene$5,7,12,14$-tetraone (DAPTO) in $1989,{ }^{11}$ no further synthetic derivatizations of this interesting scaffold were reported during the 20th century. 
Substantial interest in diazapentacenes only aroused after the successful incorporation of DHDAP into OFETs by Nuckolls and coworkers in 2003, who reported a p-type field-effect mobility of $5 \times 10^{-5} \mathrm{~cm}^{2} \mathrm{~V}^{-1} \mathrm{~s}^{-1}$. Follow-up studies by Miao and coworkers in 2009 revealed the pronounced dependency of the charge carrier mobility on the crystallinity of DHDAP with a different polymorph exhibiting hole mobilities up to $0.45 \mathrm{~cm}^{2} \mathrm{~V}^{-1} \mathrm{~s}^{-1}$.4,6 The oxidized congener DAP was also investigated as a p-type semiconducting material in OFETs; however, only poor mobilities in the range of $10^{-5} \mathrm{~cm}^{2} \mathrm{~V}^{-1} \mathrm{~s}^{-1}$ were found. ${ }^{12}$

Since the first demonstration of the field-effect mobility of DHDAP, considerable efforts have been directed towards the functionalization of $\mathrm{N}$-heteropentacenes in order to tune the chemical as well as electronic properties in a desirable fashion. A variety of $\mathrm{N}$-heteropentacenes have been synthesized and investigated as functional materials in organic electronic devices. ${ }^{7,13}$ Till today, however, only a few functionalized DAP derivatives have been reported, most of which show a p-type semiconducting behavior, while their n-type counterparts still remain scarce.

Our research focuses on symmetrically substituted DAPs, although less symmetrical derivatives are also known. ${ }^{14}$ In 1989, the highly symmetrical bisquinone derivative DAPTO was synthesized by Bayyuk and coworkers. ${ }^{11}$ Recently, Bunz and coworkers reported an updated synthesis of this compound and its subsequent derivatization with acetylides. ${ }^{15}$ The first halogenated DAPs were synthesized in 2009 by Tao and coworkers. ${ }^{5}$ The authors reported on $5,7,12,14$ tetrachloro-6,13-diazapentacene (TCDAP) and its reduced dihydro congener (TCDHDAP). Both compounds were used as p-channel materials in organic thin-film transistors (OTFTs) with hole mobilities reaching up to 0.13 and $1.4 \mathrm{~cm}^{2} \mathrm{~V}^{-1} \mathrm{~s}^{-1}$, respectively. Two years later, Tao and coworkers fabricated OFETs using single crystals of TCDAP to reveal thatdepending on the device fabrication-the compound can also be used as an n-channel semiconductor with high electron mobilities reaching up to $3.39 \mathrm{~cm}^{2} \mathrm{~V}^{-1} \mathrm{~s}^{-1}$. The transistors worked under ambient conditions, which demonstrated the high stability of the material. ${ }^{16}$ To the best of our knowledge, this was the first and up to now the only report on $\mathrm{n}$-channel behavior of a DAP derivative. In 2014 Wang and coworkers reported nearly insoluble 5,7,12,14-tetrabromo6,13-dihydro-6,13-diazapentacene (1) and used it as a precursor for Stille cross-couplings with alkylthiophenes. ${ }^{17}$ The resulting compounds were the first reported arylsubstituted DHDAPs. In this work, the compounds were subsequently transformed into unprecedented $\mathrm{BN}$-heterocoronenes through electrophilic borylation. Nevertheless, the involved tetraarylated DHDAPs were not investigated in terms of their semiconductor properties in OFETs.

In the present work, we aimed at tailoring the electronic properties of DAP by lateral arylation. While we recently reported the synthesis and characterization of various 5,7,12,14-tetraaryl-substituted DAPs, ${ }^{15}$ we focus herein on the synthesis and characterization of 5,7,12,14-tetraphenylsubstituted DHDAP 2 and DAP 3 (Scheme 1). Through comparison of the characteristics of $\mathbf{2}$ and $\mathbf{3}$ with those of the previously reported all-carbon congener 5,7,12,14tetraphenylpentacene (TPP), ${ }^{18,19}$ we assessed the impact of the nitrogen incorporation on the molecular properties. In addition, we provide detailed insights into the OFET device performance of $\mathbf{2}$ and $\mathbf{3}$.

\section{Results and Discussion}

The synthetic route towards tetraphenyl-substituted $\mathbf{2}$ is depicted in Scheme 1. Compound $\mathbf{1}$ is accessible via electrophilic bromination of parent DHDAP according to a literature procedure. ${ }^{17}$ Subsequently, 1 was subjected to a Suzuki cross-coupling reaction with phenylboronic acid under conditions that were slightly modified from those reported previously. ${ }^{15}$ The title compound 5,7,12,14-tetraphenyl-6,13-dihydro-6,13-diazapentacene (2) was obtained as a yellow solid after chromatographic purification followed by several recrystallizations from $\mathrm{CH}_{2} \mathrm{Cl}_{2} /$ hexanes. The compound was soluble in common organic solvents to give solutions showing intense blue fluorescence. The dihydro compound $\mathbf{2}$ is prone to spontaneous oxidation when handled in solution under ambient conditions in air, which is indicated by a slow color change from yellow to light green. To prevent the undesired oxidation, either the use of deoxygenated solvents or the addition of hydrazine was required. In particular, the addition of hydrazine was inevitable during the chromatographic purification of 2.

To investigate the influence of nitrogen incorporation into the pentacene scaffold, the oxidation of 2 towards fully $\pi$ conjugated $\mathbf{3}$ was targeted. Besides the previously reported

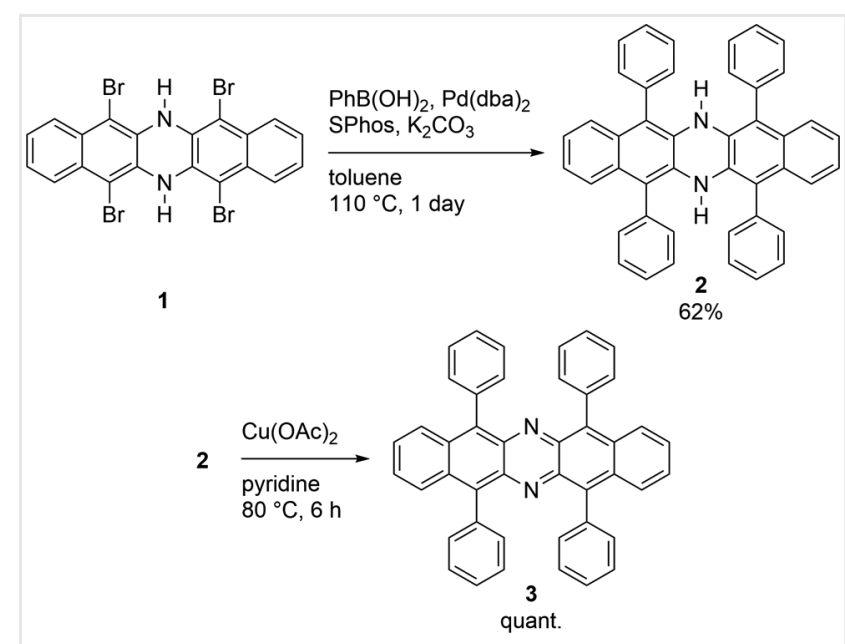

Scheme 1 Synthesis of tetraphenyl-substituted DHDAP 2 and oxidation towards DAP 3. 
oxidation with $\mathrm{MnO}_{2},{ }^{15}$ compound 2 can be easily oxidized with copper(II) acetate in warm pyridine in quantitative yield (Scheme 1). Nevertheless, the reaction time should not exceed 6 hours, since after that time gradual decomposition is observed, as judged by thin-layer chromatography. Both compounds $\mathbf{2}$ and $\mathbf{3}$ are stable in the solid state under ambient conditions in air, and melt with decomposition at $420^{\circ} \mathrm{C}$ and $336^{\circ} \mathrm{C}$, respectively, as determined with thermogravimetry/ differential scanning calorimetry (TGA/DSC) analyses [see the Supplementary Information (SI) for details]. The chemical identity of 2 and 3 was confirmed by ${ }^{1} \mathrm{H}$ and ${ }^{13} \mathrm{C}$ NMR spectroscopy as well as high-resolution mass spectrometry. The electronic properties of both compounds were investigated by UV-vis spectroscopy and cyclic voltammetry (CV).

We were successful in growing single crystals suitable for X-ray crystallographic analysis for both compounds 2 and $3 .^{15}$ The obtained crystal structure for compound 2 occupies the triclinic space group P-1 (Figure 1a, c; see SI for details). The diazapentacene core is planar, resembling the crystal structure of previously reported diazapentacenes. ${ }^{12}$ The phenyl substituents are arranged virtually parallel to each other and highly twisted with respect to the diazapentacene backbone with torsion angles of $67^{\circ}$ and $81^{\circ}$. Compound 2 shows high structural similarity with the all-carbon TPP congener. ${ }^{18}$ As a result of the nearly orthogonal orientation of the lateral phenyls, only negligible electronic communication with the $\pi$-system of the DHDAP core is expected. In the crystal packing, the molecules of 2 arrange in one-dimensional slipped stacks along the diazapentacene short molecular axis, without $\pi-$ $\pi$ overlap and an interplanar distance of $4.80 \AA$ between two diazapentacene cores (Figure 1c). Taking a closer look at the slipped stacks, two molecules are shifted from each other by $3.3 \AA$ along the diazapentacene long molecular axis, due to the steric hindrance of the phenyl rings. Thereby, $\mathrm{C}\left(\mathrm{sp}^{2}\right)-\mathrm{H} \cdot . \pi \mathrm{\pi}$ edge-to-face interactions between the phenyls and the core $\pi$-system are observed, with a

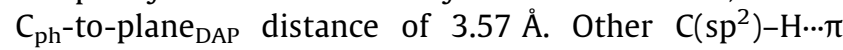
interactions are observed between the outer diazapentacene core protons and the phenyl $\pi$-system of adjacent stacks, with a $C_{D_{A P}}$-to-plane ${ }_{P h}$ distance of $3.62 \AA$. The geometry of 2 predicted by density functional theory (DFT) calculations at the $\omega B 97 \mathrm{X}-\mathrm{D}^{20} /$ def2-TZVP ${ }^{21}$ level is comparable to the geometry revealed by X-ray crystallography, with only a slight deviation observed for the spatial orientation of the lateral phenyls, while no significant differences for the diazapentacene core are discernible (Figure S11).

The fully aromatic derivative $\mathbf{3}$ arranges in face-to-face stacked dimers in the solid state (Figure $1 \mathrm{~b}$, see SI for details), with considerable $\pi-\pi$ overlap between the two diazapentacene cores as indicated by an interplanar distance of $3.55 \AA$. Along the long molecular axis, the two molecules are slipped about $3.31 \AA$ with respect to each other. The nitrogen centers in $\mathbf{3}$ are perfectly planar, while the outer annulated phenyl rings are slightly bent (by roughly $2^{\circ}$ and $5^{\circ}$; Figure S10a). Similar to compound 2 , the phenyl substituents in $\mathbf{3}$ are highly twisted with respect to the diazapentacene core with dihedral angles of around $60^{\circ}$, indicating weak electronic communication between the $\pi$ systems. In contrast to the dihydro congener $\mathbf{2}$, the phenyl substituents in $\mathbf{3}$ appear tilted with respect to each other, rather than parallel. This arrangement allows for $\pi-\pi$ interaction between the adjacent phenyls with a distance of 3.21 $\AA$ and an edge-to-face interaction with a $\mathrm{C}_{\mathrm{Ph}}-$ to- $\pi$ face $_{\mathrm{Ph}}$ distance of $3.68 \AA$ (Figure S10b). The dimers of 3 arrange in one-dimensional slipped stacks with an interplanar distance of $4.79 \AA$ and no $\pi-\pi$ overlap between the stacked dimers (Figure 1d; see SI for details). Neighboring stacks do not show any $\pi-\pi$ interactions either; however, $C$ $\left(\mathrm{sp}^{2}\right)-\mathrm{H} \cdots \pi$ interactions can be assumed between the adjacent phenyl moieties.
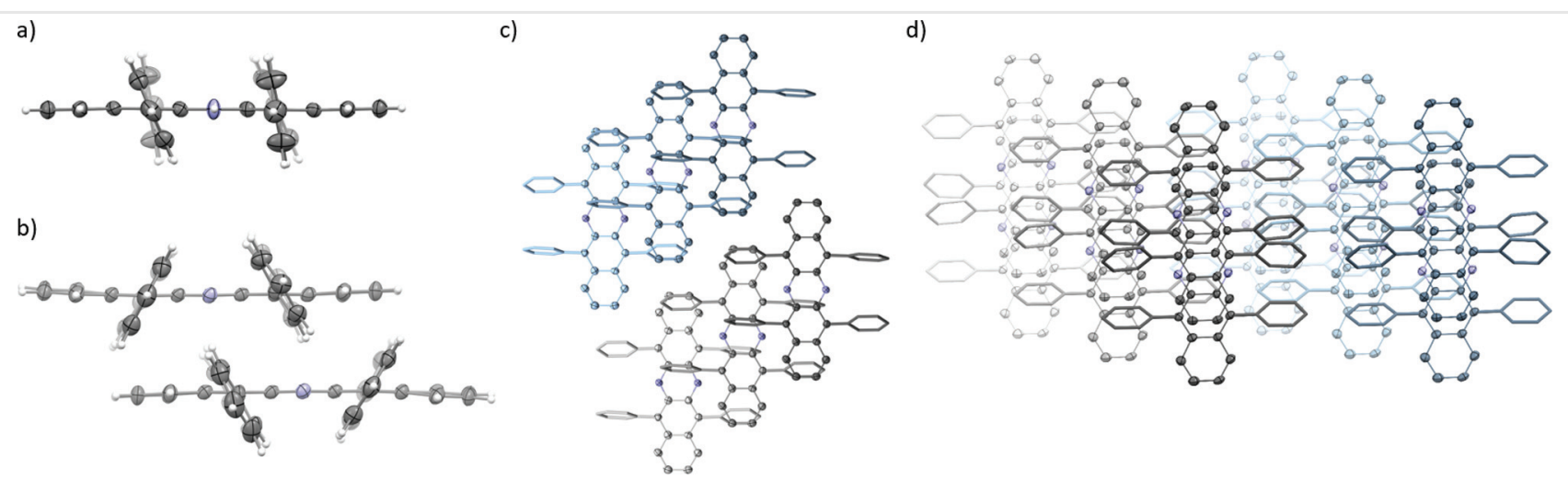

Fig. 1 X-Ray molecular structures of $\mathbf{2}$ (a) and $\mathbf{3}$ (b) and the solid-state packing motifs of $\mathbf{2}$ (c) and $\mathbf{3}$ (d) (ORTEP plots drawn at the 50\% probability level and hydrogen atoms are represented by a sphere of arbitrary size. Different colors are used to indicate the spatial orientation. Color code: grey or turquoise $=$ carbon, blue $=$ nitrogen, white $=$ hydrogen. Hydrogen atoms and solvent molecules in the packing diagrams are omitted for clarity. Solidstate packing motifs viewed perpendicular to the diazapentacene planes). 


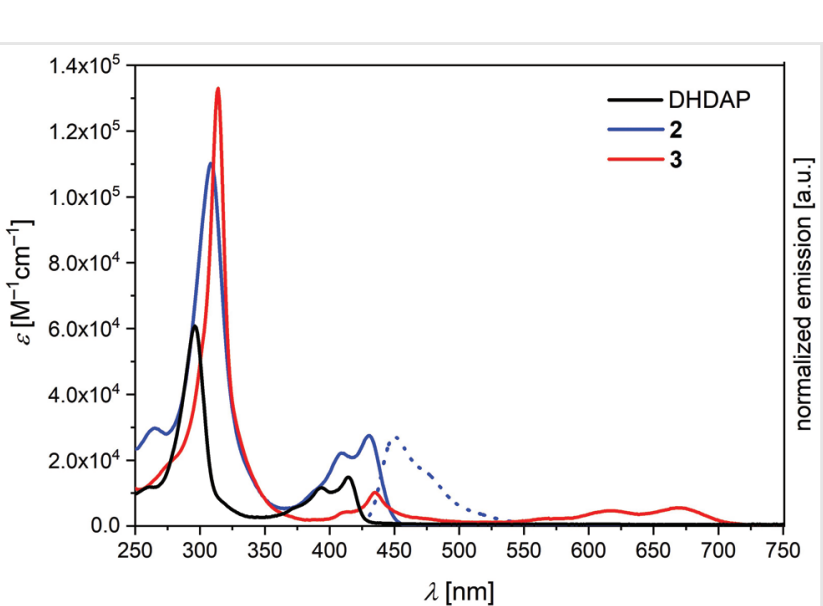

Fig. 2 UV-vis absorption (bold) and emission (dotted) spectra of DHDAP, 2, and 3 measured in $\mathrm{CH}_{2} \mathrm{Cl}_{2}$ solutions. Extinction coefficients of DHDAP are multiplied by a factor of 200 for illustration purpose.

UV-vis spectroscopy was used to explore the electronic influence of phenylation on the DAP core (Figure 2). Furthermore, the data allow for evaluation of the influence of nitrogen substitution in the pentacene core upon comparison to all-carbon TPP. The UV-vis absorption spectrum of DHDAP in $\mathrm{CH}_{2} \mathrm{Cl}_{2}$ shows a characteristic maximum intensity absorption in the high-energy region at $296 \mathrm{~nm}$ and a longest wavelength absorption maximum $\left(\lambda_{\max }\right)$ in the mid-energy region at $414 \mathrm{~nm}$. Calculations within time-dependent (TD) ${ }^{22}$ DFT approximation at the $\omega B 97 X-D^{20} /$ def2-TZVP 21 level of theory show that the HOMO to LUMO transition is mainly responsible for the lowest energy band (see SI for details). For DHDAP an optical HOMO-LUMO gap $\left(E_{\mathrm{g}}\right)$ of $2.90 \mathrm{eV}$ was estimated from the onset of the UV-vis absorption ( $\lambda_{\text {on }}$; Table 1$)$.
Compound 2 displays a nearly identical UV-vis spectrum compared to DHDAP (Figure 2). The nature of the involved electronic transitions is very similar according to DFT calculations, i.e. the lowest energy band has the largest contribution from the HOMO to LUMO transition. All absorption bands exhibit only a small redshift of about $15 \mathrm{~nm}$ (compared to the calculated value of $11 \mathrm{~nm}$ at TD $\omega B 97 X-D^{20} /$ def2-TZVP ${ }^{21}$ ), indicating only limited electronic communication between the phenyl substituents and the diazapentacene core, due to the highly twisted conformation of the phenyl moieties. The small redshift of the absorption spectrum of $\mathbf{2}$ in comparison to DHDAP reveals the slightly smaller HOMO-LUMO gap of 2 of $2.77 \mathrm{eV}$ (Table 1). Compound 2 shows blue emission in $\mathrm{CH}_{2} \mathrm{Cl}_{2}$ with an emission maximum at $450 \mathrm{~nm}$, corresponding to a Stokes shift of $1034 \mathrm{~cm}^{-1}$ (Figure 2). The quantum yield is about 0.44 .

The fully aromatic derivative 3 shows the same absorptions in the high- and mid-energy regions, with a small redshift of $5 \mathrm{~nm}$ compared to compound 2 . The largest contribution to the mid-energy band is from the HOMO-2 to LUMO transition according to TD DFT calculations, which also confirms a small redshift with respect to 2 . Furthermore, compound 3 absorbs in the low-energy region between 550 and $700 \mathrm{~nm}$. The observed fine structure with three peaks at 568,616 , and $670 \mathrm{~nm}$ resembles the typical pentacene absorption pattern. ${ }^{19}$ This low-energy band corresponds mainly to the HOMO to LUMO transition. Thus, fully aromatic DAP 3 has a significantly smaller HOMO-LUMO gap of $1.75 \mathrm{eV}$, compared to its dihydro congener $\mathbf{2}$ (2.90 eV). In comparison to TPP, ${ }^{19}$ nitrogen substitution leads to a redshift of the absorption bands of about $50 \mathrm{~nm}$, indicating a significant change in the electronic properties, e.g., a narrowing of the HOMO-LUMO gap (Table 1).

To evaluate the energy levels of the frontier molecular orbitals (FMOs) of 2 and 3, CV measurements in $\mathrm{CH}_{2} \mathrm{Cl}_{2}$

Table 1 Photophysical and electrochemical data of DHDAP, DAP, 2, 3, and TPP

\begin{tabular}{|c|c|c|c|c|c|c|}
\hline Compound & $\lambda_{\max }(\mathrm{nm})$ meas. $^{\mathrm{a}} /$ calc. $^{\mathrm{b}}$ & $E_{g}(\mathrm{eV})$ meas. $^{\mathrm{c}} / \mathrm{calc}^{\mathrm{b}}$ & $E_{\mathrm{ox}}(\mathrm{V})$ meas. $^{\mathrm{d}} /$ calc. $^{\mathrm{e}}$ & $E_{\text {red }}(\mathrm{V})$ meas. ${ }^{\mathrm{d}} / \mathrm{calc}^{\mathrm{e}}$ & $E_{\text {Hомо }}{ }^{f}(e V)$ & $E_{\text {LUMO }}{ }^{f}(\mathrm{eV})$ \\
\hline DHDAP & $414 / 345$ & $2.90 / 3.59$ & $-0.17^{g}$ & - & $-4.63^{9}$ & -1.73 \\
\hline DAP & $615^{h} / 552$ & $1.93^{h} / 2.25$ & - & $-1.17^{\mathrm{h}}$ & $-5.56^{\mathrm{h}, \mathrm{i}}$ & $-3.63^{\mathrm{h}, \mathrm{i}}$ \\
\hline 2 & $430 / 356$ & $2.77 / 3.48$ & $0.07,0.69 / 0.1,1.4$ & - & -4.87 & -2.10 \\
\hline 3 & $670 / 595$ & $1.75 / 2.08$ & 0.63 & $-1.30,-1.72 /-1.3,-2.4$ & -5.43 & -3.68 \\
\hline TPPj & 621 & 1.88 & $0.64,1.18$ & -1.41 & -4.95 & -3.07 \\
\hline
\end{tabular}

aLongest wavelength absorption peak in $\mathrm{CH}_{2} \mathrm{Cl}_{2}$.

${ }^{b}$ Calculated at $\omega$ B97X-D. TD DFT approximation used for excited-state properties (see SI for details). Theoretical optical band gap was taken equal to the lowest-energy bright transition (corresponds to theoretical $\lambda_{\max }$ ).

'Calculated from the onset of the UV-vis absorption.

${ }^{\mathrm{d}}$ Oxidation and reduction half-wave potentials determined by $\mathrm{CV}$ in $\mathrm{CH}_{2} \mathrm{Cl}_{2}$ with $0.1 \mathrm{Mn}-\mathrm{Bu}_{4} \mathrm{NPF}_{6}$ as supporting electrolyte and ferrocene as internal standard.

${ }^{e}$ Calculated at $\omega$ B97X-D. Theoretical values are reduction potentials for one-electron reductions of the corresponding species (see SI for details).

${ }_{\mathrm{F}} \mathrm{FMO}$ estimated as follows: HOMO level estimated from the first oxidation potential according to $E_{\mathrm{HOMO}}=-\left(E_{\mathrm{ox}}+4.8\right)$ eV. Potentials vs. Fc/Fc ${ }^{+}$. LUMO level

estimated from $E_{\mathrm{HOMO}}$ and $E_{\mathrm{g}}$.

${ }^{9}$ Data taken from Tang et al. ${ }^{4}$

hData taken from Liu et al. ${ }^{12}$

iHOMO level estimated from $E_{\text {LUMO }}$ and $E_{\mathrm{g}}$. LUMO level estimated from the reduction potential.

'Data taken from Kaur et al. ${ }^{19}$ 


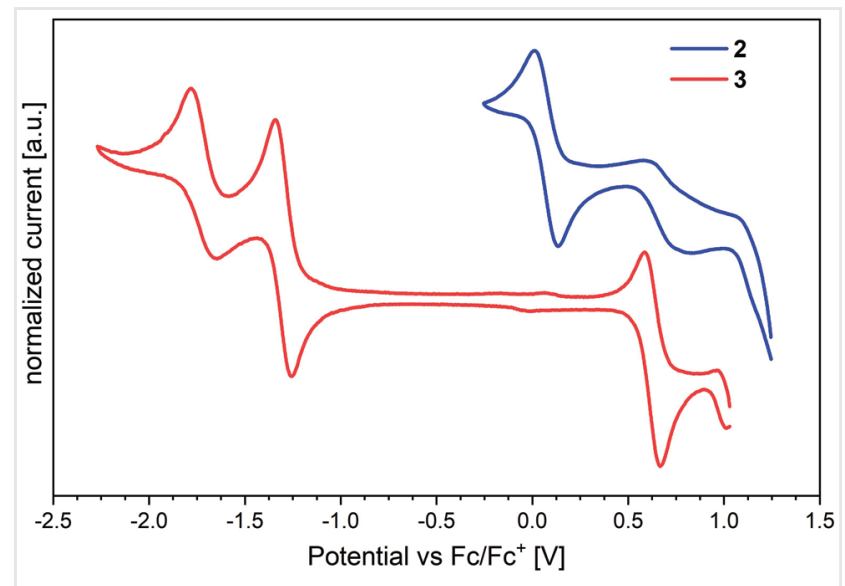

Fig. 3 Normalized cyclic voltammograms of $\mathbf{2}$ and $\mathbf{3}$ measured in $\mathrm{CH}_{2} \mathrm{Cl}_{2}\left(\sim 1.5 \mathrm{mM} ; 0.1 \mathrm{M} \mathrm{n}-\mathrm{Bu}_{4} \mathrm{NPF}_{6}\right.$ as supporting electrolyte; scan rate of $\left.100 \mathrm{mV} \mathrm{s}^{-1}\right)$.

( $1.5 \mathrm{mM}$ ) were performed (Figure 3 ). Compound 2 shows two reversible oxidations, most likely corresponding to the stepwise oxidations of the nitrogen atoms, with half wave potentials of $+0.07 \mathrm{~V}$ and $+0.69 \mathrm{~V}$ [all potentials are referenced against the ferrocene/ferrocenium $\left(\mathrm{Fc} / \mathrm{Fc}^{+}\right)$ redox couple]. The low value of the first oxidation potential classifies 2 as a very good electron donor comparable to ferrocene. The DFT-calculated reduction potential of $+0.1 \mathrm{~V}$ for the radical cation $\mathbf{2}^{+}$is in good agreement with the experimental value (see Table 1 and SI for details). Under the premise that the HOMO energy level of ferrocene is $4.8 \mathrm{eV}$ below the vacuum level, the HOMO energy level of 2 is located at $-4.87 \mathrm{eV}$. In combination with the optical bandgap, a LUMO energy level of $-2.10 \mathrm{eV}$ is obtained for $\mathbf{2}$. In comparison to the FMO energy levels of DHDAP, ${ }^{4}$ the phenyl substitution leads to a slight stabilization of both FMOs. However, the effect on the LUMO appears to be slightly stronger (Table 1).

On the other hand, compound 3 shows only one reversible oxidation at $+0.63 \mathrm{~V}$ within the potential window of $\mathrm{CH}_{2} \mathrm{Cl}_{2}$ (ca. -2.0 to $+2.0 \mathrm{~V}$ ), which corresponds to a HOMO located at $-5.43 \mathrm{eV}$. The comparison to TPP shows that the incorporation of the two nitrogen atoms to the 6- and 13-positions of the pentacene skeleton significantly stabilizes both the HOMO and LUMO energy levels (Table 1 ). Hence, compound $\mathbf{3}$ is more easily reduced, which is nicely illustrated by the two reversible reductions occurring at $-1.30 \mathrm{~V}$ and $-1.72 \mathrm{~V}$. While the first reduction potential of $\mathbf{3}$ is well reproduced by the DFT-calculated value of $-1.3 \mathrm{~V}$ (Table 1 ), the second reduction is not reliably approximated due to the difficulties in theoretical treatment of solvated highly charged species. The reversibility of the reductions as observed by $\mathrm{CV}$ indicates the potential of the tetraphenyl-substituted DAP 3 to serve as an n-channel material in organic electronic devices. Moreover, the LUMO energy level of $-3.68 \mathrm{eV}$ estimated from the experimental data suggests possible n-type semiconducting behavior of $3^{23}$ Interestingly, the calculated first adiabatic electron affinity (EA) of $\mathbf{3}$ in vacuum is $2.2 \mathrm{eV}$, while the second $\mathrm{EA}$ is negative $(-1.1 \mathrm{eV})$ indicating that the dianion is stable only in solution. A comparison of the theoretical FMO energy levels of parent DAP and $\mathbf{3}$ shows that the substitution with phenyl moieties leads to an increase of the HOMO energy level, while the LUMO is mostly unaffected (see Table 1 and SI for details).

Considering the localization of the Kohn-Sham HOMO and LUMO on the diazapentacene core (see SI for details), calculations support the experimental observations that phenyl substitution has only a smaller influence on the photophysical properties in comparison to oxidation of the diazapentacene core. However, the phenyl substitution has a pronounced impact on the chemical stability and the solid-state packing, which are two important factors for electronic device applications.

To investigate the influence of oxidation (i.e. aromatization) of the DAP core on the film-forming properties, the surface morphology of $\mathbf{2}$ and $\mathbf{3}$ were analyzed by atomic force microscopy (AFM). Both compounds were deposited on a self-assembled monolayer of $n$-octadecyltrichlorosilane (OTS) on $\mathrm{Si} / \mathrm{SiO}_{2}$ substrates under the same conditions via physical vapor deposition to avoid difference in the micro- and macrostructure due to the variation of the processing technique. A thickness of $50 \mathrm{~nm}$ was chosen as an optimum, ensuring layer continuity and better discernible X-ray diffraction patterns. For thicker films, additional undesired bulk resistance effects in devices with topcontact architecture can be observed. The AFM images show clear differences in the film microstructure of compounds 2 and 3 (Figure 4). While compound 2 forms a continuous layer with a fine granular topography, with grains of around $125 \mathrm{~nm}$ in size, compound $\mathbf{3}$ forms larger polycrystalline domains with an average diameter of $1.9 \mu \mathrm{m}$ but with limited continuity. The individual crystals of $\mathbf{3}$ are distributed randomly without any distinct macroscopic orientation on the surface, leading to the high film

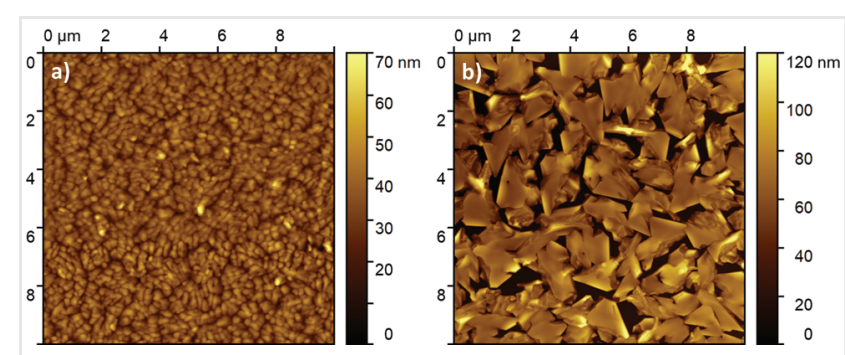

Fig. 4 AFM height images of thin films on OTS-modified $\mathrm{Si} / \mathrm{SiO}_{2}$ substrate prepared via physical vapor deposition of compounds 2 (a) and $\mathbf{3}(\mathrm{b})$. The black areas visible in the image of $\mathbf{3}$ correspond to the $\mathrm{Si} / \mathrm{SiO}_{2}$ substrate. Both images show a section of $10 \times 10 \mu \mathrm{m}$. 
roughness of $16.3 \mathrm{~nm}$. On the other hand, for compound 2 , $5.2 \mathrm{~nm}$ rough films were obtained. Consequently, the surface coverage of 2 reaches almost $100 \%$, while for 3 the coverage is around $82 \%$. Overall, compound $\mathbf{3}$ shows a stronger tendency to form large crystalline domains with well-defined grain boundaries that might significantly facilitate the charge carrier transport, due to reduction of trapping effects. In comparison to compound 3, material 2 forms a homogeneous polycrystalline layer.

To elucidate the effect of aromatization on the molecular organization in thin solid films when going from $\mathbf{2}$ to $\mathbf{3}$, grazing-incidence wide-angle X-ray scattering (GIWAXS) measurements were performed (Figure 5). Both compounds show comparable interstack distances determined from the main reflection (100 according to the Miller's index) localized at the meridional plane. However, absence of the higher order reflection h00 suggests a lack of long-range organization of the individual molecules. The interstack distance found for compound 2 of $1.21 \mathrm{~nm}$ resembles the value reported for unsubstituted DHDAP $(1.29 \mathrm{~nm}){ }^{6}$ The decrease of the interstack distance most likely originates from tilting of $\mathbf{2}$ with respect to the substrate in edge-on organization. Reflections in the GIWAXS pattern of $\mathbf{2}$ localized at $q_{\mathrm{xy}}$ $=0.77 \AA^{-1}$ and $q_{z}=0.1 \AA^{-1}$ (d-spacing of $0.78 \mathrm{~nm}$ ) and $q_{\mathrm{xy}}=0.87 \AA^{-1}$ and $q_{\mathrm{z}}=0 \AA^{-1}$ (d-spacing of $0.71 \mathrm{~nm}$ ) correspond to the intrastack distances of the slipped molecules, which is in good agreement with the $a$ parameter of the single-crystal unit cell of $\mathbf{2}$. The organization in the $\pi$ stacking direction could not be confirmed by GIWAXS measurements due to the high number of low-intensity reflections in the wide-angle range. For compound 3, a shorter interlayer distance of $1.16 \mathrm{~nm}$ was determined. The d-spacing of the out-of-plane reflection decreases going from 2 to 3 due to the higher inclination of the molecular cores. This finding suggests that the long axis of $\mathbf{3}$ is more tilted with respect to the substrate than in the case of compound 2. Additionally, the intrastack distance for compound 3 is increased to $0.94 \mathrm{~nm}$ $\left(q_{\mathrm{xy}}=0.68 \AA^{-1}\right.$ and $q_{\mathrm{z}}=0 \AA^{-1}$ ) compared to $0.78 \mathrm{~nm}$ observed for compound 2 . This difference may result from the tilting of the molecule or, as discussed above for the singlecrystal structures, the formation of supramolecular dimers. In contrast to compound 2, a $\pi$-stacking reflection of $0.37 \mathrm{~nm}$ was observed on the off-equatorial plane $\left(q_{\mathrm{xy}}=1.42 \AA^{-1}\right.$ and $q_{\mathrm{z}}=1.10 \AA^{-1}$ ), confirming the organization of the molecules in a slipped fashion (tilting with respect to the out-of-plane direction). In summary, the lack of full $\pi$-conjugation in the dihydro compound $\mathbf{2}$ changes the tilting angle of the molecular core with respect to the substrate, as judged by the variation in the inter- and intrastack distances, which consequently influences the self-assembly properties and the surface morphology.

To elucidate the semiconducting properties of $\mathbf{2}$ and $\mathbf{3}$, both compounds were studied in OTFTs. Thin films of $50 \mathrm{~nm}$ were deposited on OTS-modified $\mathrm{Si} / \mathrm{SiO}_{2}$ substrates via
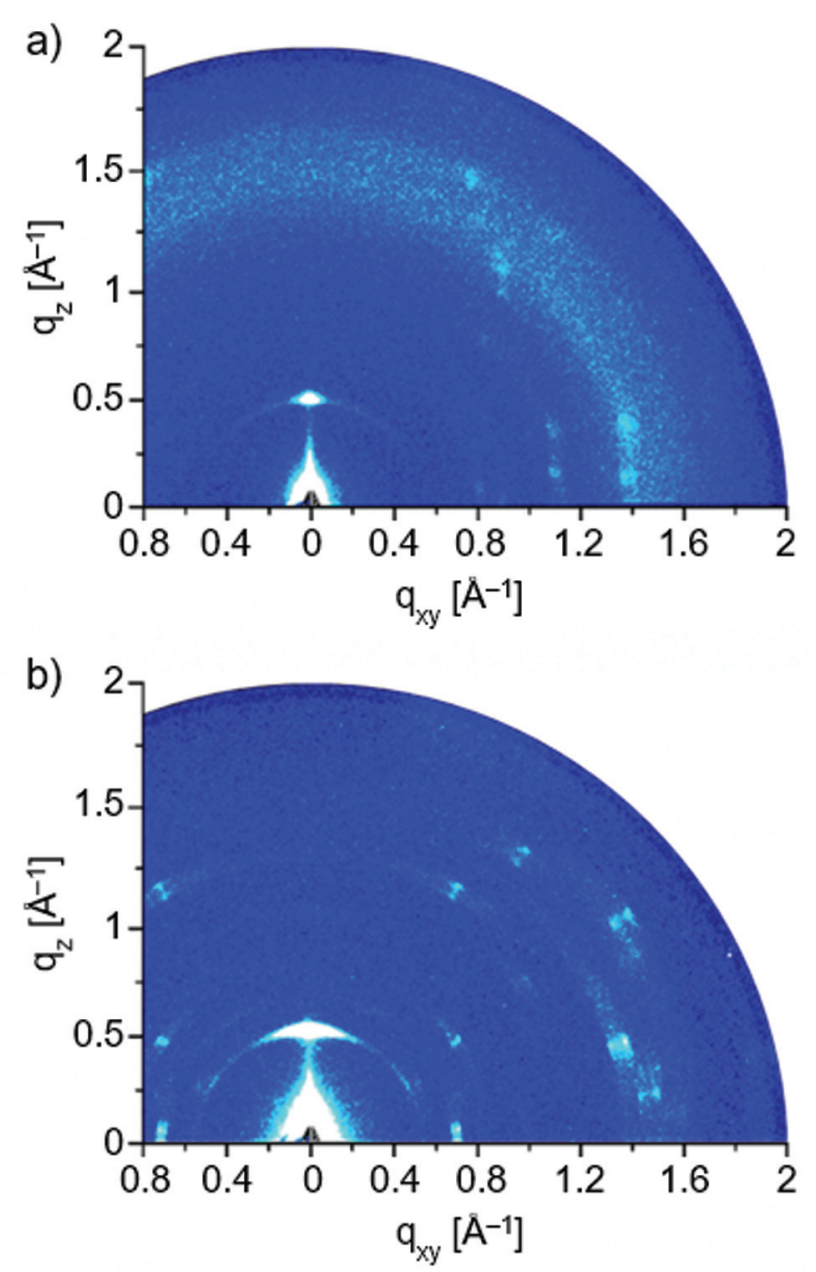

Fig. 5 GIWAXS patterns of compounds $\mathbf{2}$ (a) and $\mathbf{3}$ (b) deposited on $\mathrm{Si} / \mathrm{SiO}_{2}$ substrates.

thermal evaporation of the semiconductor material under high vacuum. Furthermore, source and drain electrodes were deposited via thermal evaporation under high vacuum as well. Device characterization measurements were performed under a nitrogen atmosphere. In the current studies, fieldeffect transistors based on compound 2 showed a p-type semiconducting behavior, with a maximum hole mobility of $3.5 \times 10^{-3} \mathrm{~cm}^{2} \mathrm{~V}^{-1} \mathrm{~s}^{-1}$, a threshold voltage of $-34 \mathrm{~V}$, and an on/off ratio on the level of $10^{4}$ (Table 2 ). The average hole

Table 2 Average charge carrier mobility $\left(\mu_{\text {av }}\right)$, maximum charge carrier mobility $\left(\mu_{\text {max }}\right)$, threshold voltage $\left(V_{\text {th }}\right)$, and on/off ratio

\begin{tabular}{|c|c|c|c|c|}
\hline Compound & $\begin{array}{l}\mu_{\max } \\
\left(10^{-3} \mathrm{~cm}^{2} \mathrm{~V}^{-1} \mathrm{~s}^{-1}\right)\end{array}$ & $\begin{array}{l}\mu_{\mathrm{av}} \\
\left(10^{-3} \mathrm{~cm}^{2} \mathrm{v}^{-1} \mathrm{~s}^{-1}\right)\end{array}$ & $V_{\text {th }}(\mathrm{V})$ & On/off \\
\hline 2 & 3.5 (hole) & $2.5 \pm 0.4$ & -34 & $10^{4}$ \\
\hline 3 & 3.3 (electron) & $1.8 \pm 0.5$ & +38 & $10^{4}$ \\
\hline
\end{tabular}


mobility calculated for 12 devices was $(2.5 \pm 0.4) \times 10^{-3} \mathrm{~cm}^{2}$ $\mathrm{V}^{-1} \mathrm{~s}^{-1}$. In other words, the dihydro compound 2 retains the p-type nature of parent DHDAP, ${ }^{4}$ with the hole mobilities being in the same range as those reported for all-carbon TPP. ${ }^{18}$

The hole mobility might be negatively affected by high contact resistance at the gold electrode/semiconductor interface as manifested by non-ohmic behavior evident from the output characteristics at low $V_{\mathrm{DS} .}{ }^{24}$ Additionally, the charge transport may be influenced by the polycrystalline nature of the film with many grain boundaries, which makes charge carrier transport less effective. ${ }^{25}$

Compound 3 showed electron transport behavior with a maximum electron mobility of $3.2 \times 10^{-3} \mathrm{~cm}^{2} \mathrm{~V}^{-1} \mathrm{~s}^{-1}$, a threshold voltage of $+38 \mathrm{~V}$, and an on/off ratio on the level of $10^{4}$. The average electron mobility calculated for 12 transistors was $(1.8 \pm 0.5) \times 10^{-3} \mathrm{~cm}^{2} \mathrm{~V}^{-1} \mathrm{~s}^{-1}$. Thus, the introduction of the two nitrogen atoms into the fully conjugated pentacene core changes the character of the charge transport from hole to electron transport. ${ }^{26}$ The charge carrier values observed for both $\mathbf{2}$ and $\mathbf{3}$ are considerably lower compared to the highest value reported for unsubstituted DHDAP., ${ }^{4}$ This can be explained by two factors, both related to a crystalline lattice disorder localized next to the dielectric/semiconductor interface. ${ }^{27,28}$ Such effect is observed when the drain current determined at output characteristics decreases after pinch-off voltage is reached. This decrease intensifies in the saturation region as the drain-source voltage increases (Figure 6). The first factor for the drain current decrease is an effect of increasing participation of monolayers located closest to the interface in creating a conducting channel while $V_{\mathrm{DS}}$ increases. The first few layers of semiconductor material at the dielectric interface usually show much lower molecular ordering than the semiconductor layers in the bulk above. This results in an appearance of mobility gradients in the direction perpendicular to the dielectric/semiconductor interface, having a significant impact on the shapes of current-voltage character-
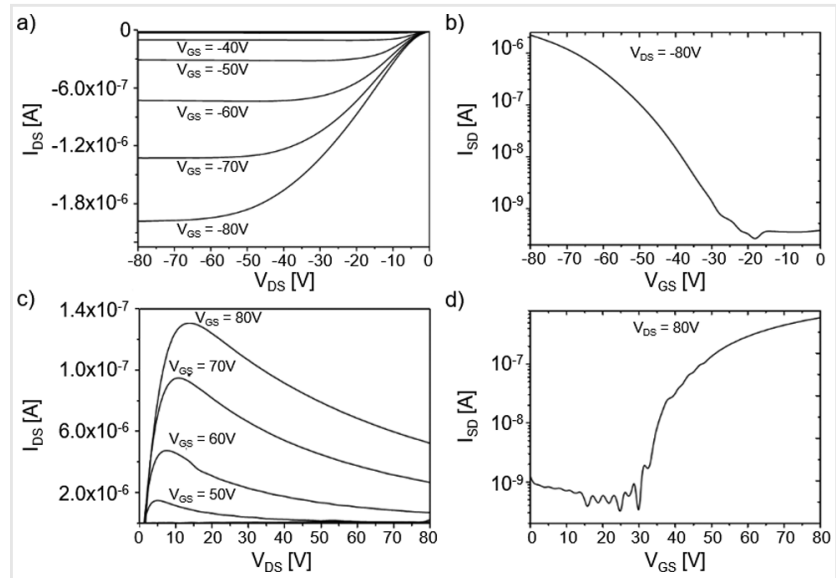

Fig. 6 Output (left) and transfer (right) characteristics for the p-type compound $\mathbf{2}(\mathrm{a}, \mathrm{b})$ and the n-type compound $\mathbf{3}$ (c, d). istics. $^{29}$ The second factor is related to the trapping of charge carriers by interface dipoles that influences the shape of the output characteristics. ${ }^{28,30}$ The interface dipoles of adsorbed guest molecules can locally destroy the order of neighboring host molecules and create local traps on host molecules even if guest molecules do not create chemical traps themselves. Similar to the first factor, local disorders and traps result in appearance of mobility gradients in the direction perpendicular to the dielectric/semiconductor interface. Molecular disorder and local trap depth decrease with the distance from the interface. ${ }^{29,30}$

\section{Conclusions}

In summary, 5,7,12,14-tetraphenyl-substituted 6,13dihydro-6,13-diazapentacene $\mathbf{2}$ and its fully aromatic DAP congener 3 were synthesized. To assess the impact of arylation along with the nitrogen incorporation on the molecular characteristics and solid-state structures, the compounds were examined by UV-vis spectroscopic, electrochemical, and X-ray crystallographic studies which were corroborated by DFT calculations. The thin films fabricated from $\mathbf{2}$ and $\mathbf{3}$ were characterized with respect to their morphology (AFM) and molecular organization (GIWAXS). Both compounds were implemented into OTFTs to evaluate their charge carrier mobilities. In spite of rather low measured mobilities in the range of $10^{-3} \mathrm{~cm}^{2} \mathrm{~V}^{-1} \mathrm{~s}^{-1}$, the measurements revealed that the fully aromatic derivative behaved as an n-type material while the dihydro congener retained the p-type character of parent DHDAP. The hole and electron transport behavior of functionalized DAP scaffolds can be reversed through redox chemistry between the dihydro and the fully aromatic form. Hence, in our future efforts we will expand this principle to different substitution patterns in order to further improve the device performance of this interesting class of organic semiconductors.

\section{Experimental Section}

All reagents and solvents were purchased at reagent grade from commercial suppliers and were used without further purification unless otherwise noted. For thin-layer chromatography, aluminum plates coated with $0.20 \mathrm{~mm}$ silica gel containing a fluorescent indicator (MachereyNagel, ALUGRAM ${ }^{\circledR}$, SIL G/UV 254 ) were used and visualized by exposure to ultraviolet light $(\lambda=254$ and $365 \mathrm{~nm})$. Column chromatography was performed on silica gel (Macherey-Nagel, M-N Silica Gel 60A, 230-400 mesh). Melting points were determined by means of TGA/DSC analysis, measured on a METTLER Toledo TGA/DSC1 device. IR spectra were recorded on a Varian 660-IR spectrometer in ATR mode. NMR spectra were recorded on a Bruker Avance 
300 (Bruker, $300 \mathrm{MHz}$ for ${ }^{1} \mathrm{H}$ ) or Bruker Avance 400 (Bruker, $100 \mathrm{MHz}$ for ${ }^{13} \mathrm{C}$ ) spectrometer. Chemical shifts $(\delta)$ are reported in parts per million (ppm) referenced to the residual solvent signals as an internal reference $\left(\mathrm{CD}_{2} \mathrm{Cl}_{2}\right.$ : $5.32 \mathrm{ppm}$ for ${ }^{1} \mathrm{H}$ and $53.8 \mathrm{ppm}$ for $\left.{ }^{13} \mathrm{C}\right)$. Mass spectra were recorded on an Ultraflex TOF/TOF (Bruker, LDI) or MicroTOF II (Bruker, HR ESI and APPI) mass spectrometer. UV-vis absorption spectra were measured on a Varian Cary 5000 spectrophotometer. Fluorescence spectra were recorded on a Jasco FP-8500 spectrofluorometer equipped with an integrating sphere (ILF-835 | $100 \mathrm{~mm}$ ). Electrochemical data were obtained by CV measurements on a computercontrolled BASi Cell Stand instrument under a nitrogen atmosphere using a standard three-electrode assembly connected to a potentiostat. In this setup, a Pt working electrode, a Pt wire as the counter electrode, and $\mathrm{Ag} / \mathrm{AgNO}_{3}$ as the reference electrode were used. Cyclic voltammograms were obtained for compound solutions in deoxygenated $\mathrm{CH}_{2} \mathrm{Cl}_{2}(\sim 1.5 \mathrm{mM})$ with $n-\mathrm{Bu}_{4} \mathrm{NPF}_{6}(\sim 0.1 \mathrm{M})$ as the supporting electrolyte, at a scan rate of $50,100,150$, or $200 \mathrm{mV} \mathrm{s}^{-1}$. Ferrocene was used as an internal standard, thus all potentials are referenced to the ferrocene/ferrocenium $\left(\mathrm{Fc} / \mathrm{Fc}^{+}\right)$redox couple. X-ray crystallographic data were measured on a Supernova CCD diffractometer (Agilent). The structures were solved with the ShelXT ${ }^{31}$ structure solution program using Intrinsic Phasing and refined with the ShelXL ${ }^{32}$ refinement package using Least Squares minimization. After full-matrix least-square refinement of the non-hydrogen atoms with anisotropic thermal parameters, the hydrogen atoms were placed in calculated positions using a riding model. CCDC 1982202 (2) and 1958306 (3) contain the supplementary crystallographic data for this article. These data are provided free of charge by the Cambridge Crystallographic Data Centre (https:// www.ccdc.cam.ac.uk/).

\section{Procedures}

\section{5,7,12,14-Tetraphenyl-6,13-dihydro-6,13- diazapentacene (2)}

To a deoxygenated mixture of toluene $(10 \mathrm{~mL})$ and aq. $2 \mathrm{M} \mathrm{K}_{2} \mathrm{CO}_{3}$ ( $8 \mathrm{~mL}$ ), 1 (1 equiv., $0.27 \mathrm{~g}, 0.45 \mathrm{mmol}$ ), $\mathrm{PhB}(\mathrm{OH})_{2}$ (6 equiv., $0.33 \mathrm{~g}, 2.7 \mathrm{mmol}), \mathrm{Pd}(\mathrm{dba})_{2}(0.1$ equiv., $33 \mathrm{mg}$, $0.057 \mathrm{mmol}$ ), and SPhos ( 0.1 equiv., $23 \mathrm{mg}, 0.056 \mathrm{mmol}$ ) were added subsequently. The mixture was heated to $110{ }^{\circ} \mathrm{C}$ for 1 day. After cooling to room temperature, the phases were separated. The organic phase was diluted with a $\mathrm{CH}_{2} \mathrm{Cl}_{2}$ /hydrazine in THF ( $1 \mathrm{M}$ ) mixture (1 vol\% hydrazine, deoxygenated, $100 \mathrm{~mL}$ ) and filtered over a plug of $\mathrm{SiO}_{2}$. After evaporation of the solvent under reduced pressure, the obtained yellow-orange residue was recrystallized from hot $\mathrm{CH}_{2} \mathrm{Cl}_{2}$ (1 vol\% hydrazine, $50 \mathrm{~mL}$ ) layered with hexanes
(100 mL) at $8{ }^{\circ} \mathrm{C}$. The product was obtained as yellow crystals $(0.163 \mathrm{~g}, 0.278 \mathrm{mmol}, 62 \%)$.

M.p. $=420{ }^{\circ} \mathrm{C}$ (melting with decomp.).

IR (ATR): 3387, 3052, 3020, 1594, 1461, 1425, 1265, 1205 , $1151,1068,1027,750,696 \mathrm{~cm}^{-1}$.

${ }^{1} \mathrm{H}$ NMR $\left(\mathrm{CD}_{2} \mathrm{Cl}_{2}, 300 \mathrm{MHz}\right): \delta=7.37-7.31(\mathrm{~m}, 12 \mathrm{H})$, 7.15-7.12 (m, 8H), 7.02-6.99 (m, 4H), 6.95-6.90 (m, 4H), $5.65(\mathrm{~s}, 2 \mathrm{H}) \mathrm{ppm}$.

${ }^{13} \mathrm{C}$ NMR $\left(\mathrm{CD}_{2} \mathrm{Cl}_{2}, 100 \mathrm{MHz}\right): \delta=135.0,130.7,130.0,129.7$, 128.5, 128.0, 124.4, 123.7, $118.2 \mathrm{ppm}$.

HRMS (ESI, $\mathrm{CH}_{2} \mathrm{Cl}_{2}$ ): $m / z[\mathrm{M}]^{+}$calcd for $\mathrm{C}_{44} \mathrm{H}_{30} \mathrm{~N}_{2}: 586.2404$; found: 586.2404 .

Anal. calcd. for $\mathrm{C}_{44} \mathrm{H}_{30} \mathrm{~N}_{2}$ : C $90.07 \%$, H 5.15\%, N 4.77\%; found: C $89.73 \%$, H $5.22 \%$, N $4.53 \%$.

\section{5,7,12,14-Tetraphenyl-6,13-diazapentacene (3)}

A mixture of 2 (1 equiv., $39 \mathrm{mg}, 0.066 \mathrm{mmol}$ ) and $\mathrm{Cu}$ (OAc) 2 (2 equiv., $24 \mathrm{mg}, 0.13 \mathrm{mmol}$ ) in pyridine $(5 \mathrm{~mL}$ ) was heated to $80^{\circ} \mathrm{C}$ for $5.5 \mathrm{~h}$. After cooling to room temperature, the mixture was poured into aq. $2.2 \mathrm{M} \mathrm{HCl}(50 \mathrm{~mL})$. The green precipitate was extracted with $\mathrm{CH}_{2} \mathrm{Cl}_{2}(2 \times 50 \mathrm{~mL})$. The combined organic phases were washed with sat. aq. $\mathrm{NH}_{4} \mathrm{Cl}(50 \mathrm{~mL})$, dried over $\mathrm{MgSO}_{4}$, and the solvent was evaporated under reduced pressure. In order to remove remaining pyridine, the obtained solid was dissolved in $\mathrm{CH}_{2} \mathrm{Cl}_{2}(100 \mathrm{~mL})$. The solution was washed with aq. $1.7 \mathrm{M}$ $\mathrm{HCl}(3 \times 20 \mathrm{~mL})$ and $\mathrm{H}_{2} \mathrm{O}(2 \times 20 \mathrm{~mL})$, dried over $\mathrm{MgSO}_{4}$, and the solvent evaporated under reduced pressure. The product was obtained as dark green solid (39 mg, $0.066 \mathrm{mmol}$, quant.).

M.p. $=336{ }^{\circ} \mathrm{C}$ (melting with decomp.).

IR (ATR): 3387, 3054, 1438, 1396, 1265, 1072, 1027, 763, $694 \mathrm{~cm}^{-1}$.

${ }^{1} \mathrm{H} \quad \mathrm{NMR}\left(\mathrm{CD}_{2} \mathrm{Cl}_{2}, 300 \mathrm{MHz}\right): \delta=7.99-7.95(\mathrm{~m}, 4 \mathrm{H})$, 7.49-7.45 (m, 8H), 7.44-7.41 (m, 12H), 7.32-7.29 (m, 4H) ppm.

${ }^{13} \mathrm{C}$ NMR $\left(\mathrm{CD}_{2} \mathrm{Cl}_{2}, 100 \mathrm{MHz}\right): \delta=138.8,138.7,137.3,133.1$, 132.7, 128.0, 127.9, 127.4, $126.6 \mathrm{ppm}$.

HRMS (APPI, $\mathrm{CH}_{2} \mathrm{Cl}_{2}$ ): $m / z[\mathrm{M}]^{+}$calcd for $\mathrm{C}_{44} \mathrm{H}_{28} \mathrm{~N}_{2}$ : 584.2247; found: 584.2246 .

\section{Computational Details}

Geometry optimizations were performed at the $\omega \mathrm{B} 97 \mathrm{X}$ $\mathrm{D}^{20} /$ def2-TZVP ${ }^{21}$ level of theory with the Gaussian $09^{33}$ program suite. Zero-point vibrational energies (ZPVEs), thermal corrections to enthalpy, and entropies were calculated at $\omega B 97 X-D^{20} /$ def2-SVP $^{21}$ on the $\omega$ B97X-D/def2-SVPoptimized geometries. Small imaginary frequencies below $20 \mathrm{~cm}^{-1}$ were ignored. Open-shell systems were calculated using unrestricted DFT. Excited-state calculations were 
performed at the TD ${ }^{22} \omega \mathrm{B} 97 \mathrm{X}-\mathrm{D} / \mathrm{def} 2-\mathrm{TZVP}$ level of theory. Solvent effects were calculated at $\omega$ B97X-D/def2-TZVP using the conductor-like polarizable continuum model (C-PCM) ${ }^{34}$ and gas-phase geometries. Structures were visualized with Chemcraft $1.8,{ }^{35}$ which was also used to calculate root-meansquare deviations (RMSDs) between geometries. For other computational details, see the SI.

\section{Fabrication of Transistors}

\section{Substrate Modification}

$\mathrm{Si} / \mathrm{SiO}_{2}$ substrates $(300 \mathrm{~nm})$ were modified by selfassembled monolayer of OTS. Prior the functionalization substrates were cleaned in piranha solution. The process was carried out in a mixture of chloroform and $n$-hexane in a ratio of $1: 4$ and in the presence of OTS in relation to the volume of the mixture of $1: 200$. The substrates were kept in the solution for 30 minutes and then rinsed three times with chloroform in an ultrasonic cleaner and then dried under a nitrogen flux. Solvents (AR grade) and OTS were purchased from Sigma-Aldrich and used without further purification.

\section{Thin-Film Deposition}

Both compounds were deposited under the same conditions. Thin films of $50 \mathrm{~nm}$ (indicated by quartz crystal microbalance calibrated on pentacene) were thermally evaporated under high vacuum with the growth rate of $0.1 \AA \mathrm{s}^{-1}$ and substrate temperature of $60^{\circ} \mathrm{C}$. The process was carried out in MBraun MB-ProVap-7 evaporation chamber (BioNanoPark in Lodz, Poland).

\section{Electrode Deposition}

Transistors were prepared in top-contact/bottom-gate configuration. The $50 \mathrm{~nm}$ thick source and drain electrodes were thermally evaporated under high vacuum with the growth rate of $1.0 \mathrm{~nm} \mathrm{~s}^{-1}$. Gold electrodes were selected for the p-type compound (compound 2 ) and silver one for the n-type compound (compound 3), respectively. Ossila E325 linear shadow source-drain masks with variable channel length from 10 to $30 \mu \mathrm{m}$ and channel width of $1 \mathrm{~mm}$ were used.

\section{Film Morphology}

Surface morphology images of physically evaporated films were made using the Dimension 3100 Atomic Force Microscope. The measurements were made in semi-contact mode with Olympus silicon scanning probes at $320 \mathrm{kHz}$ resonance frequency. AFM images were analyzed with the use of Gwyddion Open source software for SPM data analysis.

\section{Field-Effect Measurements}

OFET measurements were performed by using a Keithley $2634 \mathrm{~B}$ source meter. Transfer characteristics were measured under a nitrogen atmosphere in the range of $\mathrm{V}_{\mathrm{GS}}$ from 0 to $80 \mathrm{~V}$ for the n-type compound and in the range of $\mathrm{V}_{\mathrm{GS}}$ from 0 to $-80 \mathrm{~V}$ for the p-type one. The same range of changes was used for $V_{\mathrm{DS}}$ during output characteristics measurements. The charge carrier mobility was derived from transfer characteristics $\left(\left|V_{\mathrm{DS}}=80 \mathrm{~V}\right|\right)$ in the saturation regime. For each sample, 12 transistors were measured and average values calculated. Current fluctuations observed below the threshold voltage are associated with current values below the meter's sensitivity.

\section{X-Ray Diffraction Measurements}

GIWAXS experiments were performed by means of a solid anode X-ray tube (Siemens Kristalloflex X-ray source, copper anode X-ray tube operated at $30 \mathrm{kV}$ and $20 \mathrm{~mA}$ ), Osmic confocal MaxFlux optics, and X-ray beam with pinhole collimation system. The data were recorded on the MAR345 image plate detector during 3 h exposure time. Data analysis was performed using the Datasqueeze software.

\section{Funding Information}

This study was supported by the Deutsche Forschungsgemeinschaft (DFG; Project number 182849149-SFB 953 "Synthetic Carbon Allotropes" and Project number 281029004-SFB 1249 "N-Heteropolyzyklen als Funktionsmaterialien").

\section{Acknowledgment}

M.B. and T.M. acknowledge the Foundation for Polish Science financed by the European Union under the European Regional Development Fund (POIR.04.04.00-003ED8/17-01).

\section{Supporting Information}

Supporting information for this article is available online at https://doi.org/10.1055/s-0040-1713856.

\section{References}

(1) (a) Kelley, T. W.; Muyres, D. V.; Baude, P. F.; Smith, T. P.; Jones, T. D. Mater. Res. Soc. Symp. Proc. 2003, 771, 169. (b) Anthony, J. E. Chem. Rev. 2006, 106, 5028. (c) Anthony, J. E. Angew. Chem. Int. Ed. 2008, 47, 452. 
(2) (a) Maliakal, A.; Raghavachari, K.; Katz, H.; Chandross, E.; Siegrist, T. Chem. Mater. 2004, 16, 4980. (b) Stevens, B.; Perez, R. S.; Ors, J. A. J. Am. Chem. Soc. 1974, 96, 6846.

(3) Miao, Q.; Nguyen, T.-Q.; Someya, T.; Blanchet, G. B.; Nuckolls, C.J. Am. Chem. Soc. 2003, 125, 10284.

(4) Tang, Q.; Zhang, D.; Wang, S.; Ke, N.; Xu, J.; Yu, J. C.; Miao, Q. Chem. Mater. 2009, 21, 1400.

(5) Weng, S.-Z.; Shukla, P.; Kuo, M.-Y.; Chang, Y.-C.; Sheu, H.-S.; Chao, I.; Tao, Y.-T. ACS Appl. Mater. Interfaces 2009, 1, 2071.

(6) Miao, Q. Synlett 2012, 23, 326.

(7) (a) Bunz, U. H. F.; Engelhart, J. U.; Lindner, B. D.; Schaffroth, M. Angew. Chem. Int. Ed. 2013, 52, 3810. (b) Bunz, U. H. F. Acc. Chem. Res. 2015, 48, 1676. (c) Li, J.; Zhang, Q. ACS Appl. Mater. Interfaces 2015, 7, 28049. (d) Bunz, U. H. F.; Engelhart, J. U. Chem. Eur. J. 2016, 22, 4680. (e) Bunz, U. H. F.; Freudenberg, J. Acc. Chem. Res. 2019, 52, 1575. (f) Li, J.; Chen, S.; Wang, Z.; Zhang, Q. Chem. Rec. 2016, 16, 1518. (g) Zhang, Z.; Zhang, Q. Mater. Chem. Front.2020 (e-pub ahead of print). Doi: 10.1039/C9QM00656G.

(8) Miao, Q. Adv. Mater. 2014, 26, 5541.

(9) Hinsberg, O. Justus Liebigs Ann. Chem. 1901, 319, 257.

(10) VanAllan, J. A.; Adel, R. E.; Reynolds, G. A. J. Org. Chem. 1962, 27, 2873.

(11) Katritzky, A. R.; Fan, W.-Q.; Li, Q.-L.; Bayyuk, S. J. Heterocycl. Chem. 1989, 26, 885.

(12) Liu, D.; Li, Z.; He, Z.; Xu, J.; Miao, Q. J. Mater. Chem. 2012, 22, 4396.

(13) (a) Liang, Z.; Tang, Q.; Xu, J.; Miao, Q. Adv. Mater. 2011, 23, 1535. (b) Chu, M.; Fan, J.-X.; Yang, S.; Liu, D.; Ng, C. F.; Dong, H.; Ren, A.M.; Miao, Q. Adv. Mater. 2018, 30, 1803467. (c) Reiss, H.; Ji, L.; Han, J.; Koser, S.; Tverskoy, O.; Freudenberg, J.; Hinkel, F.; Moos, M.; Friedrich, A.; Krummenacher, I.; Lambert, C.; Braunschweig, H.; Dreuw, A.; Marder, T. B.; Bunz, U. H. F. Angew. Chem. Int. Ed. 2018, 57, 9543.

(14) (a) Schwaben, J.; Münster, N.; Klues, M.; Breuer, T.; Hofmann, P.; Harms, K.; Witte, G.; Koert, U. Chem. Eur. J. 2015, 21, 13758. (b) Engelhart, J. U.; Lindner, B. D.; Tverskoy, O.; Rominger, F.; Bunz, U. H. F. Chem. Eur. J. 2013, 19, 15089. (c) Müller, M.; Beglaryan, S. S.; Koser, S.; Hahn, S.; Tverskoy, O.; Rominger, F.; Bunz, U. H. F. Chem. Eur. J. 2017, 23, 7066.

(15) Xie, G.; Hauschild, M.; Hoffmann, H.; Ahrens, L.; Rominger, F.; Borkowski, M.; Marszalek, T.; Freudenberg, J.; Kivala, M.; Bunz, U. H. F. Chem. Eur. J. 2020, 26, 799.

(16) Islam, M. M.; Pola, S.; Tao, Y.-T. Chem. Commun. 2011, 47, 6356.

(17) Wang, X.-Y.; Zhuang, F.-D.; Wang, R.-B.; Wang, X.-C.; Cao, X.-Y.; Wang, J.-Y.; Pei, J. J. Am. Chem. Soc. 2014, 136, 3764.

(18) Miao, Q.; Chi, X.; Xiao, S.; Zeis, R.; Lefenfeld, M.; Siegrist, T.; Steigerwald, M. L.; Nuckolls, C. J. Am. Chem. Soc. 2006, 128, 1340.

(19) Kaur, I.; Jia, W.; Kopreski, R. P.; Selvarasah, S.; Dokmeci, M. R.; Pramanik, C.; McGruer, N. E.; Miller, G. P. J. Am. Chem. Soc. 2008, 130, 16274.

(20) Chai, J.-D.; Head-Gordon, M. Phys. Chem. Chem. Phys. 2008, 10, 6615.

(21) (a) Schäfer, A.; Huber, C.; Ahlrichs, R. J. Chem. Phys. 1994, 100, 5829. (b) Schäfer, A.; Horn, H.; Ahlrichs, R. J. Chem. Phys. 1992,
97, 2571. (c) Weigend, F.; Ahlrichs, R. Phys. Chem. Chem. Phys. 2005, 7, 3297. (d) Weigend, F. Phys. Chem. Chem. Phys. 2006, 8 , 1057.

(22) (a) Bauernschmitt, R.; Ahlrichs, R. Chem. Phys. Lett. 1996, 256, 454. (b) Van Caillie, C.; Amos, R. D. Chem. Phys. Lett. 1999, 308, 249. (c) Van Caillie, C.; Amos, R. D. Chem. Phys. Lett. 2000, 317, 159. (d) Casida, M. E.; Jamorski, C.; Casida, K. C.; Salahub, D. R. J. Chem. Phys. 1998, 108, 4439. (e) Furche, F.; Ahlrichs, R. J. Chem. Phys. 2002, 117, 7433. (f) Scalmani, G.; Frisch, M. J.; Mennucci, B.; Tomasi, J.; Cammi, R.; Barone, V. J. Chem. Phys. 2006, 124, 094107. (g) Stratmann, R. E.; Scuseria, G. E.; Frisch, M. J. J. Chem. Phys. 1998, 109, 8218.

(23) Tang, M. L.; Reichardt, A. D.; Wei, P.; Bao, Z. J. Am. Chem. Soc. 2009, 131, 5264.

(24) Pesavento, P.; Chesterfield, R.; Newman, C.; Frisbie, C. J. Appl. Phys. 2004, 96, 12.

(25) (a) Verlaak, S.; Arkhipov, V.; Heremans, P. Appl. Phys. Lett. 2003, 82, 5. (b) Paulus, F. J. Mater. Chem. C 2016, 4, 1194.

(26) Wu, J. I.; Wannere, C. S.; Mo, Y.; Schleyer, Pv.; Bunz, U. H. J. Org. Chem. 2009, 74, 4343.

(27) Sworakowski, J. Chem. Phys. 2015, 456, 106.

(28) Sworakowski, J.; Bielecka, U.; Lustyk, P.; Janus, K. Thin Solid Films 2014, 571, 56.

(29) Sworakowski, J.; Nespurek, S. Macromol. Symp. 2004, 212, 113.

(30) Sworakowski, J.; Nespurek, S. Molecular Low Dimensional and Nanostructured Materials for Advanced Applications. Kluwer Academic Publisher: Dordrecht, 2002, 25-35.

(31) Sheldrick, G. M. Acta Crystallogr., Sect. A: Found. Crystallogr. 2015, $A 71,3$.

(32) Sheldrick, G. M. Acta Crystallogr., Sect. C: Cryst. Struct. Commun. 2015, C71, 3.

(33) Frisch, M. J.; Trucks, G. W.; Schlegel, H. B.; Scuseria, G. E.; Robb, M. A.; Cheeseman, J. R.; Scalmani, G.; Barone, V.; Mennucci, B.; Petersson, G. A.; Nakatsuji, H.; Caricato, M.; Li, X.; Hratchian, H. P.; Izmaylov, A. F.; Bloino, J.; Zheng, G.; Sonnenberg, J. L.; Hada, M.; Ehara, M.; Toyota, K.; Fukuda, R.; Hasegawa, J.; Ishida, M.; Nakajima, T.; Honda, Y.; Kitao, O.; Nakai, H.; Vreven, T.; Montgomery, J. A. Jr; Peralta, J. E.; Ogliaro, F.; Bearpark, M. J.; Heyd, J.; Brothers, E. N.; Kudin, K. N.; Staroverov, V. N.; Kobayashi, R.; Normand, J.; Raghavachari, K.; Rendell, A. P.; Burant, J. C.; Iyengar, S. S.; Tomasi, J.; Cossi, M.; Rega, N.; Millam, N. J.; Klene, M.; Knox, J. E.; Cross, J. B.; Bakken, V.; Adamo, C.; Jaramillo, J.; Gomperts, R.; Stratmann, R. E.; Yazyev, O.; Austin, A. J.; Cammi, R.; Pomelli, C.; Ochterski, J. W.; Martin, R. L.; Morokuma, K.; Zakrzewski, V. G.; Voth, G. A.; Salvador, P.; Dannenberg, J. J.; Dapprich, S.; Daniels, A. D.; Farkas, Ö.; Foresman, J. B.; Ortiz, J. V.; Cioslowski, J.; Fox, D. J. Revision D.01 ed. Gaussian, Inc.: Wallingford, CT, USA, 2009.

(34) (a) Cossi, M.; Rega, N.; Scalmani, G.; Barone, V. J. Comput. Chem. 2003, 24, 669. (b) Barone, V.; Cossi, M. J. Phys. Chem. A 1998, 102, 1995.

(35) Zhurko, G. A. Chemcraft - graphical program for visualization of quantum chemistry computations. Ivanovo, Russia, 2005https:// chemcraftprog.com. 